\title{
Habits and Attitudes of First Year Students at Warmia \& Mazury University, Poland regarding Healthy Lifestyle
}

\author{
Robert Podstawski ${ }^{1}$, Katarzyna Górnik ${ }^{2}$, Renata Gizinska ${ }^{3}$ \\ ${ }^{1}$ Department of Physical Education and Sport, University of Warmia \& Mazury in Olsztyn, Prawocheńskiego \\ Olsztyn, Poland. ${ }^{2}$ University of Szczecin, Faculty of Geosciences, Chair of Recreation, \\ Mickiewicza, Szczecin, Poland. ${ }^{3}$ Faculty of Technical Sciences, Chair of Machines and Separation Processes, \\ University of Warmia \& Mazury in Olsztyn, Oczapowskiego, Olsztyn, Poland.
}

\section{ARTICLE INFO}

Received

Accepted

: 14/11/2012

Published

: 29/03/2013

: 01/09/2013

\section{KEYWORD}

Health attitudes

University

Male students

Poland

\section{ABSTRACT}

Introduction: The $1^{\text {st }}$ year of university studies is the last period during which the attitudes and habits of young adults can be shaped and that is why it is so important to accurately assess their lifestyles and needs. Aim: The aim of the study was to assess the habits and attitudes of 640 first-year male students attending the Warmia \& Mazury University in Olsztyn regarding their lifestyles, health risks and possible preventive measures. Method: Students were randomly chosen from groups attending obligatory P.E. lessons. A self-administered anonymous questionnaire, containing questions regarding physical activity, personal hygiene and sanitary conditions, nutrition, stress, tobacco and alcohol use, and the students' interest in gaining knowledge on health-related topics, was used. The obtained results were characterized by descriptive statistics. Results: The majority of the students reported participating only in obligatory P.E. lessons in high school and less than a third expressed a willingness to participate in such lessons throughout their university education. Many students reported drinking alcohol regularly, even as often as every day, and nearly half of them smoked. Most students considered stressful situations to be unavoidable and a large percentage of them expressed an interest in gaining knowledge on coping with this. The overall interest in health related topics was found to be quite low. Conclusions: The habits and attitudes of $1^{\text {st }}$ year male university students are not interested in physical activity, but largely dependent on alcohol and tobacco. Despite the fact that these students expressed the need to change some behaviors and gain knowledge on a few specific health topics, their motivation to lead a healthy lifestyle can be treated as low.

(C) Medical Education Department, School of Medical Sciences, Universiti Sains Malaysia. All rights reserved.

CORRESPONDING AUTHOR: Dr Katarzyna Górnik, University of Szczecin, Faculty of Geosciences, Chair of Recreation, Mickiewicza 16, 70-383 Szczecin, Poland. Email: kgornik@o2.pl 


\section{Introduction}

Everyday behaviors and attitudes have a significant effect on our health. It is well known and documented that physical activity, nutrition, and certain psychosocial factors (i.e., hygiene, stress, smoking and alcohol consumption) play important roles in maintaining health and preventing diseases $(1,2)$. The changing lifestyles and diets of adults along with a decrease in physical activity lead to functional disturbances of the nervous, digestive, cardiovascular, and respiratory systems as well as lipid metabolism and metabolic diseases. These conditions automatically deteriorate the quality of life (3). It is a well-known fact that a sedentary lifestyle connected with a low level of physical activity has become a serious health concern in both, developed and developing countries (4). Numerous studies have revealed that physical activity can significantly diminish the risk of cardiovascular diseases, obesity, diabetes, and other chronic illnesses $(5,6)$.

In Poland and throughout the world there is a growing interest of researchers in promoting a healthy lifestyle and preventing health risks. However, not much attention has been given to young adults' health (1). From a public health perspective, university students have become important subjects in Poland (7-11) as well as other countries (12-15). The commencement of studies and time spent at the university constitute a critical moment in the promotion of a healthy lifestyle. Away from the family home and parents' influence, students more and more often make independent choices about their life and often take risky decisions associated with the abuse psychoactive substances such as alcohol, cigarettes, or drugs. In addition, due to the large amount of time spent attending university classes and studying, many students are forced to eat in a hurry and therefore consume fast food, which is high in calories and of low nutritional value (15). Moreover, this period in life also encompasses a multitude of stress factors and so it is important for students to acquire knowledge on coping with stress and assume pro-health behaviors to strengthen their overall health.
The aim of the study conducted among $1^{\text {st }}$ year male students at the University of Warmia \& Mazury (UWM) in Olsztyn was to assess their habits and attitudes towards a healthy lifestyle. The study aim was realized by attempting to answer the following question:

1. Do the students' lifestyles and attitudes promote a healthy life?

\section{Method}

\section{Ethical consideration}

The research was carried out with prior approval of the Ethical Committee of UWM, and the volunteers willingly agreed to participate in the study, which they confirmed by signing a written consent form.

\section{Study sample}

The research was conducted on a total of $6401^{\text {st }}$ year male students enrolled at the UWM in the summer semester of the 2007/2008 school year. Sixty groups of students totaling 640 men were chosen, using random selection tables (16) from a total of 250 groups attending P.E. lessons. The participants were students of various faculties and constituted over $96 \%$ of males aged 19-20 in the selected groups. This number was determined based on the technical possibilities of surveying the study participants during a single week. Only those students who, for whatever reasons, were absent on the day of the studies were excluded from the research. First year students were specifically chosen because they are a particularly valuable research group, as it is still possible to shape and alter their health attitudes and habits. Moreover, this study constitutes the fifth stage of cross-sectional studies, which have been systematically conducted biannually since 2000 (9-11). The vast majority of students were permanent residents of the WarminskoMazurskie voivodeship.

We also assessed whether the number of participants is sufficient and therefore, if the group can be considered as representative. The following formula was used for this purpose (1): 
$n=\frac{\mu_{\alpha}^{2}}{4 d^{2}}$,

Where:

$\mathrm{d}$ - maximum (acceptable) estimation error. $\mu_{\alpha}-$ value read from the normal distribution table $\mathrm{N}(0.1)$ at the accepted significance level of $1-\alpha$. for the accepted level of significance $1-\alpha=$ $0.95\left(\mu_{\alpha}=1.96\right)$ it was assumed that the estimation error does not exceed 5\% (17). The necessary amount of participants was established as 385 and therefore lower than the actual number accounted for in the studies (640). That is why the study group can be considered homogenous and representative for the population of $1^{\text {st }}$ year male UWM students.

\section{Data collection tool}

The anonymous questionnaire consisted of 27 questions (including 20 closed-ended and 7 open-ended questions). Open-ended questions enabled the students to freely express their response to the given questions. The questions dealt with issues such as: physical activity, physical fitness, nutrition, personal hygiene, sanitary conditions, alcohol and tobacco use, stress, and gaining knowledge on health. The last part of the questionnaire contained personal information including gender, age, place of residence while at university, place of permanent residence, and location as well as type of secondary school completed.

\section{Statistical analysis}

The analysis of results used descriptive statistics and statistical calculations were performed with using the Statistica PL v. 10 software package (18).

\section{Result}

The study group is characterized in table 1 . The remaining part of the study results have been divided into the following categories of human behaviors influencing health: physical activity, personal hygiene, nutrition, sanitary conditions, alcohol/tobacco use, reaction to stress, and knowledge and interest on public health. The results have been presented in tables 2-6.

The highest percentage of students reported renting accommodation (43.08\%), and approximately $1 / 3$ stated that they live at home (29.56\%). Only $21.70 \%$ of them lived on campus. The highest number of research participants were residents of large cities with a population of over 100 thousand $(28.59 \%)$. The vast majority of them were graduates of public secondary schools (67.03\%). Less than a quarter of students finished vocational schools and even fewer $(9.22 \%)$ - other types of secondary schools. The highest percentages of students were graduates of schools located in large cities $(33.86 \%)$ or big towns (20-50 thousand inhabitants $-26.96 \%$ ).

Table 1: Background information on the respondents

\begin{tabular}{|c|c|c|c|c|c|c|c|c|c|c|c|}
\hline \multicolumn{12}{|c|}{ Residence during studies } \\
\hline \multicolumn{2}{|c|}{ Dormitory } & \multicolumn{2}{|c|}{ Rented room } & \multicolumn{2}{|c|}{ Family Home } & \multicolumn{2}{|c|}{ Boarding school } & \multicolumn{2}{|c|}{ Other } & \multicolumn{2}{|c|}{ Total } \\
\hline $\mathrm{N}$ & $\%$ & $\mathrm{~N}$ & $\%$ & $\mathrm{~N}$ & $\%$ & $\mathrm{~N}$ & $\%$ & $\mathrm{~N}$ & $\%$ & $\mathrm{~N}$ & $\%$ \\
\hline 138 & 21.70 & 274 & 43.08 & 188 & 29.56 & 6 & 0.94 & 30 & 4.72 & 636 & 100 \\
\hline \multicolumn{12}{|c|}{ Place of permanent residence } \\
\hline \multirow{2}{*}{\multicolumn{2}{|c|}{ Village }} & \multicolumn{8}{|c|}{ Town population size } & \multirow{2}{*}{\multicolumn{2}{|c|}{ Total }} \\
\hline & & \multicolumn{2}{|c|}{$<20000$} & \multicolumn{2}{|c|}{$20-50000$} & & 000 & \multicolumn{2}{|c|}{$>100000$} & & \\
\hline $\mathrm{N}$ & $\%$ & $\mathrm{~N}$ & $\%$ & $\mathrm{~N}$ & $\%$ & $\mathrm{~N}$ & $\%$ & $\mathrm{~N}$ & $\%$ & $\mathrm{~N}$ & $\%$ \\
\hline 109 & 17.03 & 128 & 20.00 & 149 & 23.28 & 71 & 11.09 & 183 & 28.59 & 640 & 100 \\
\hline
\end{tabular}




\begin{tabular}{|c|c|c|c|c|c|c|c|c|c|c|c|}
\hline \multicolumn{12}{|c|}{ Place of secondary school completed } \\
\hline \multirow{2}{*}{\multicolumn{2}{|c|}{ Village }} & \multicolumn{8}{|c|}{ Town population size } & \multirow{2}{*}{\multicolumn{2}{|c|}{ Total }} \\
\hline & & \multicolumn{2}{|c|}{$<20000$} & \multicolumn{2}{|c|}{$20-50000$} & \multicolumn{2}{|c|}{$50-100000$} & \multicolumn{2}{|c|}{$>100000$} & & \\
\hline $\mathrm{N}$ & $\%$ & $\mathrm{~N}$ & $\%$ & $\mathrm{~N}$ & $\%$ & $\mathrm{~N}$ & $\%$ & $\mathrm{~N}$ & $\%$ & $\mathrm{~N}$ & $\%$ \\
\hline 22 & 3.45 & 140 & 21.94 & 172 & 26.96 & 88 & 13.79 & 216 & 33.86 & 638 & 100 \\
\hline \multicolumn{12}{|c|}{ Type of secondary school completed } \\
\hline \multicolumn{3}{|c|}{ Public Secondary School } & \multicolumn{3}{|c|}{ Vocational school } & \multicolumn{3}{|c|}{ Other Secondary School } & \multicolumn{3}{|c|}{ Total } \\
\hline $\mathrm{N}$ & & $\%$ & $\mathrm{~N}$ & & $\%$ & $\mathrm{~N}$ & & $\%$ & $\mathrm{~N}$ & & $\%$ \\
\hline 429 & & 67.03 & 152 & & 23.75 & 59 & & 9.22 & 640 & & 100 \\
\hline
\end{tabular}

\section{Physical activity}

The behaviors and attitudes of $1^{\text {st }}$ year students regarding physical activity are presented in table 2. The survey showed that almost half $(48.73 \%)$ of the students took part in only one type of physical activity during secondary school. Nearly $40 \%$ of the respondents $(37.03 \%)$ indicated two forms of physical activity, while a mere $12.66 \%$ indicated three. The vast majority of those surveyed $(82.34 \%)$ stated that they had not been forced to limit their physical activity (for example due to illness, injuries, personal matters etc). The remainder of students periodically $(15.94 \%)$ or permanently $(1.72 \%)$ limited certain forms of physical activity offered during the obligatory P.E. lessons in secondary school.

Nearly all of the questioned men (91.41\%) indicated obligatory P.E. lessons as the most frequent form of physical activity. Approximately a quarter of them declared exercising alone or sporadically with family (23.28\%). A comparable percentage of respondents participated in school and outside of school sports clubs $(19.22 \%$ and $19.84 \%$ respectively). Activities organized by collegiate sports clubs, the Society for the Propagation of Physical Culture, and other such organizations were even less popular. Very few students $(0.78 \%)$ did not take part in any kind of physical activity, and only one was involved with the Academic Sports Association (Table 2).

Due to the fact that adolescents and young adults often refrain from any forms of physical activity in secondary school as well as during their studies, the respondents were asked about the nature and form of P.E. classes attended at university. The study revealed that almost the same percentages of students believe that P.E. classes should be voluntary or obligatory for the full extent of their studies $(30.36 \%$ and $30.67 \%$ respectively). Insignificantly more students are in favor of obligatory P.E. lessons during the first two years of studies (31.30\%). Half of the surveyed students $(50.16 \%)$ did not want to participate in P.E. classes altogether. Approximately one fourth preferred university P.E. classes to be of a recreational nature (26.84\%), while a competitive sport form was indicated by only $14.38 \%$.

When we asked students to assess their level of motor fitness nearly $46 \%$ of those surveyed $(45.95 \%)$ felt that it was "very good" and $38.16 \%$ - "good". Much fewer (4.61\%) believed that their level of motor fitness was only adequate. Poor physical fitness was indicated by just nine respondents. On the opposite end of the spectrum were 62 students who believed their level of motor fitness to be outstanding (Table 2).

\section{Personal hygiene}

From the students questioned, $57.84 \%$ felt that there are adequate sanitary conditions at the UWM, while approximately a quarter felt otherwise. The remaining students $(17.24 \%)$ did not have an opinion on the subject. The highest percentage of students $(64.80 \%)$ indicated that in order to increase the level of hygiene at the 
university, it is necessary to remodel and improve the standards of the existing infrastructure. The development of the university was mentioned by $20.00 \%$ of the respondents (Table 3).

Daily hygiene including showering, brushing teeth and cleaning intimate parts of the body was considered to be the most important habit connected with good health and indicated by $89.03 \%$ of the respondents. The same and very low percentages of students $(3.06 \%)$ considered physical activity and other behaviors to be of importance. Similar and still lower percentages of students $(1.93 \%$ and $2.09 \%$ respectively) indicated proper nutrition and the cleanness and tidiness of apparel as important aspects of good health. The vast majority of those questioned $(87.54 \%)$ specified only one pro health behavior, with two and three mentioned by only a small percentage (Table 3).

Table 2: Physical activity of participation in secondary school, preferred nature during university studies, and assessment of own level

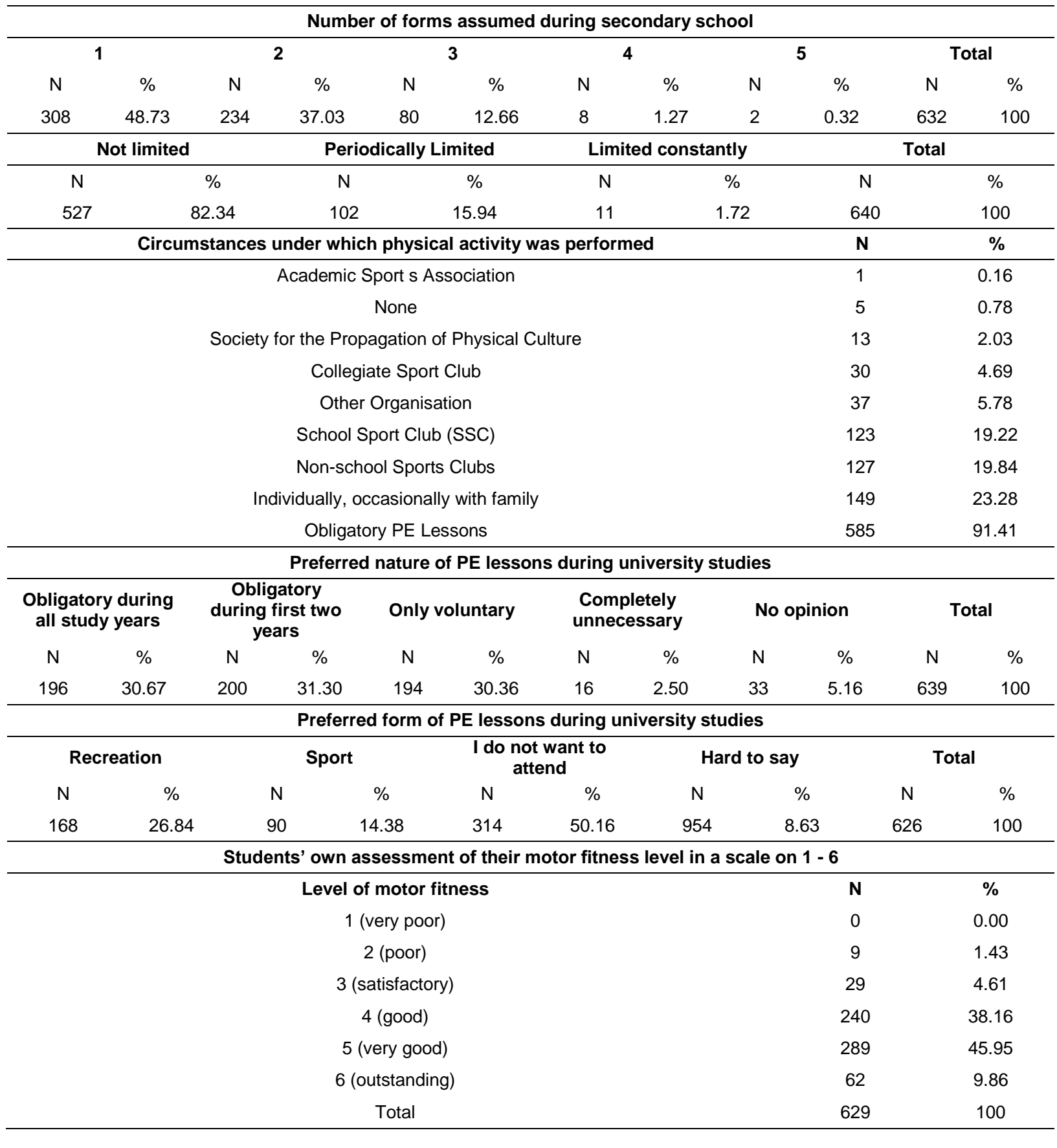


Table 3: Students' opinions on sanitary conditions at UWM and on most important pro-health activities

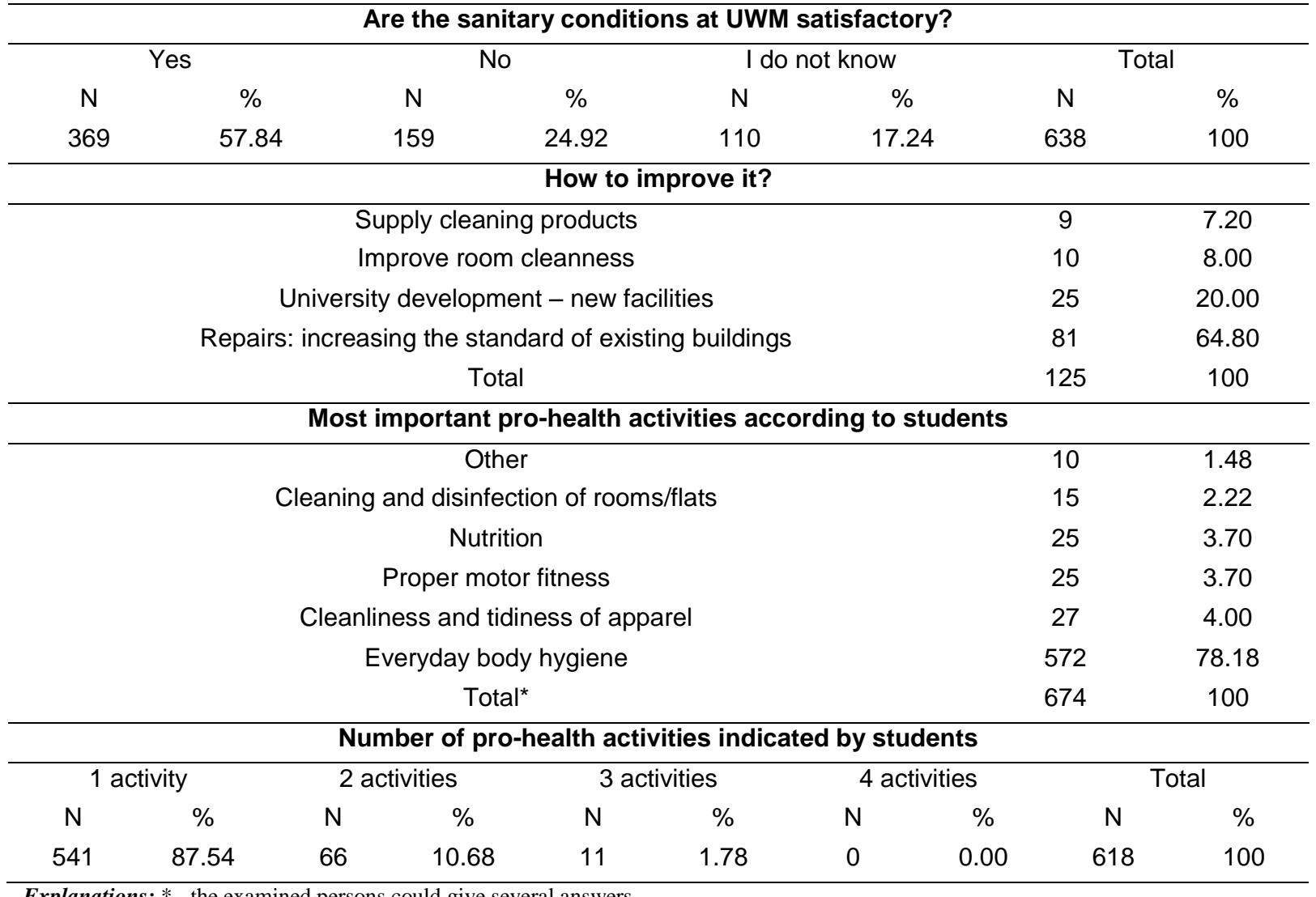

\section{Nutrition \& tobacco/alcohol use}

Table 4 presents the behaviors and attitudes of students regarding nutrition and tobacco/alcohol use. The majority of respondents felt that their present diet has a positive influence on their current and future health $(55.29 \%$ and $60.99 \%$ respectively). However, a significant portion of respondents also admitted that their dietary habits negatively affect or will affect them (29.49\% - now, $29.30 \%$ in the future). Quite a significant portion of students believed that nutrition does not influence their current health (15.22\%). Most of the students questioned (70.13\%) expressed willingness to improve their dietary habits, with the remaining $31.28 \%$ feeling otherwise.

The large majority of questioned $1^{\text {st }}$ year students $(69.69 \%)$ admitted to sporadically consuming alcohol. Only 3.08\% denied drinking alcohol altogether. Relatively high percentages admitted that they drank alcohol once a month, once a week, or as often as every day $(8.59 \%$,
$10.70 \%$, and $7.94 \%$ respectively). Over three quarters of students $(78.61 \%)$ declared drinking only one type of alcohol, and $13.61 \%$ - drank two. A wider assortment of alcohol consumed was noted by an insignificant number of respondents. Beer was the most popular alcoholic beverages $(60.73 \%)$, while similar percentages of students reported drinking wine $(11.03 \%)$ and vodka $(14.30 \%)$. Less than ten percent $(7.39 \%)$ reported consuming other forms of alcohol. Nearly all of the students $(88.59 \%)$ believed that alcohol should be readily available on campus and only $3.96 \%$ opposed this. Among the questioned men, $7.45 \%$ did not have an opinion on the matter (Table 4).

Although most students (57.10\%) were completely against smoking, $21.77 \%$ felt it was acceptable in certain situations. Approximately $10 \%$ of the respondents believed that smoking helps to relieve stress and slightly more than a half percent - that it helps socialize. Over $10 \%$ $(10.41 \%)$ felt there were other advantages to smoking. Most students who smoked (48.89\%) 
wanted to quit, but a significant percentage $(33.82 \%)$ did not feel a need to do so. The remainder of smokers did not have a clear opinion on the issue.

Table 4. Students' opinions and habits regarding nutrition, alcohol consumption and smoking

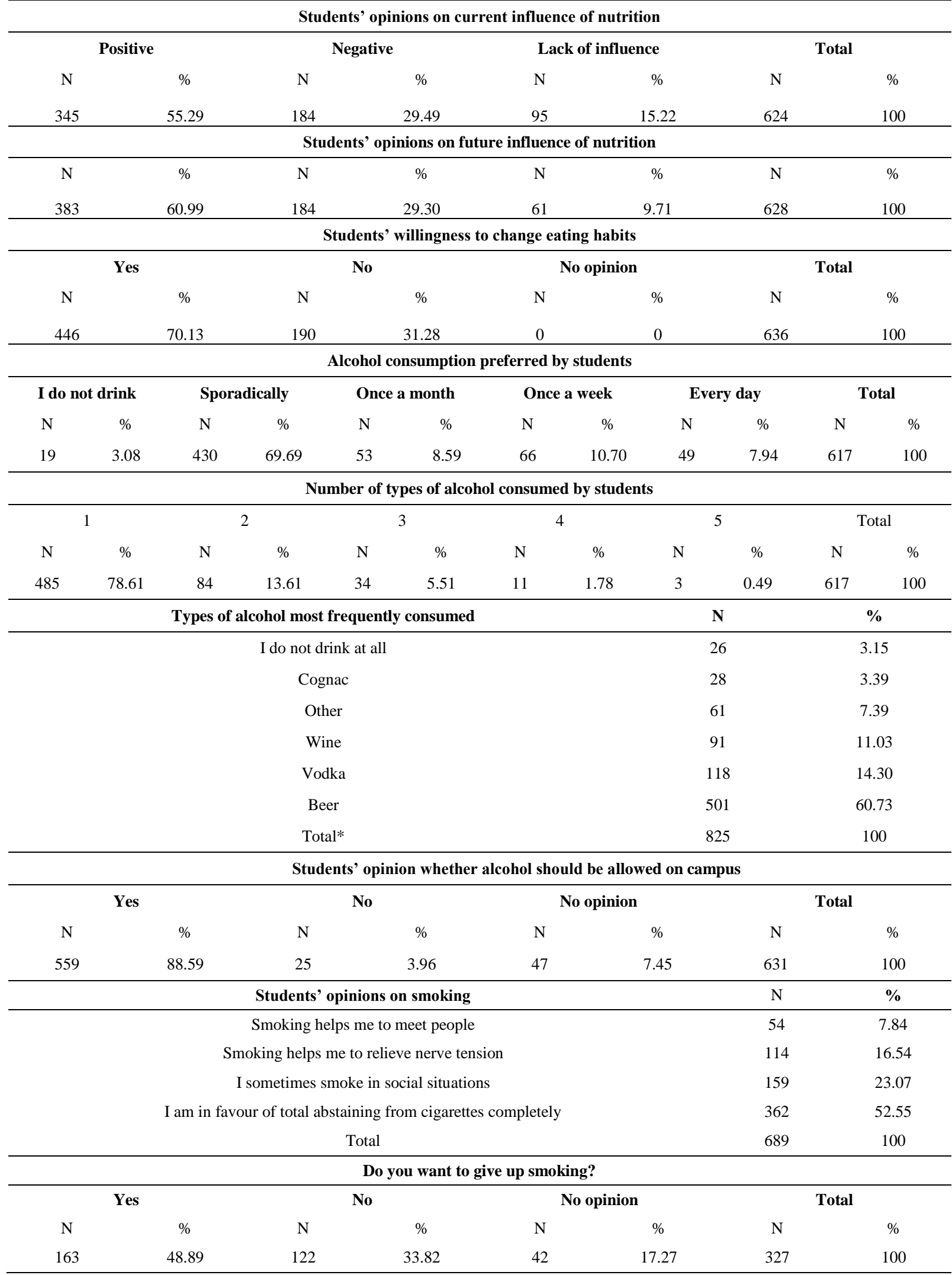

Explanations: $*$ - the examined persons could give several answers 


\section{Stress}

The opinions of students regarding stress are presented in table 4 . Nearly $70 \%$ of the students $(69.56 \%)$ agreed that it is impossible to avoid stressful situations while at university. Just over $13 \%$ of the respondents $(13.25 \%)$ were very worried about stress and $15.14 \%$ felt that they would be able to cope with it well. The majority of students $(72.2 \%)$ indicated that they were familiar with only one method of dealing with stress. Two methods were mentioned by $19.2 \%$ of respondents. Significantly fewer indicated three methods (7.26\%), with four, five, and six indicated by only a handful of students (Table 5 ). Sport was most often specified as a means of dealing with stress (18.52\%), followed by meeting with friends (15.68\%). More than $10 \%$ of students did not think about stress (10.62\%) while almost $9 \%$ claimed that stress could be reduced by using substances such as alcohol, cigarettes, and/or drugs (8.77\%).

Table 5: Students' opinions on stressful situations encountered during studies and familiar methods of coping with stress

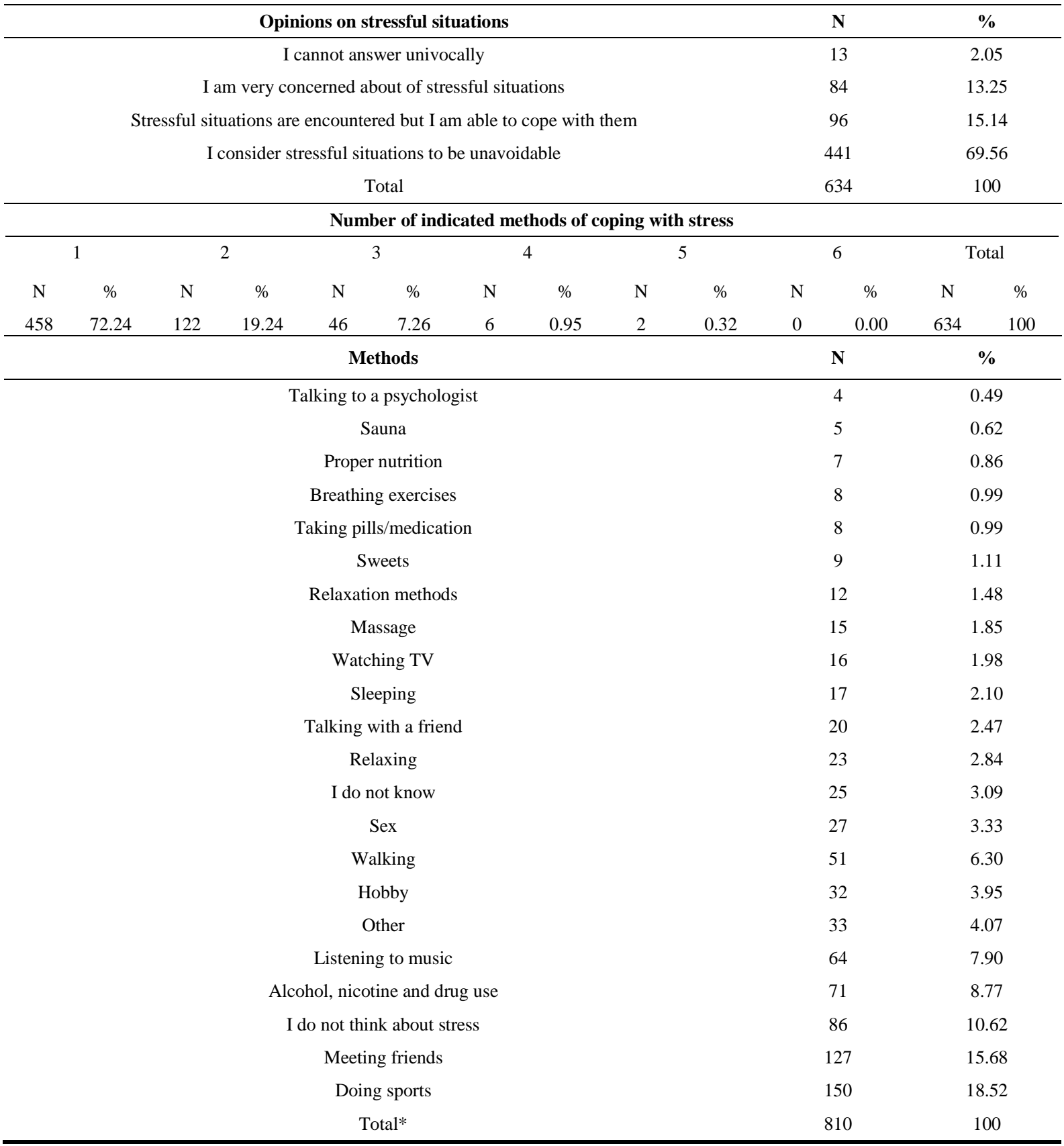

Explanations: * - the examined persons could give several answers 


\section{Knowledge regarding health care}

First year university students were very interested in gaining knowledge on the following topics: sexuality $(48.78 \%)$, social skills and manners $(46.67 \%)$, and first aid $(41.71 \%)$. The spread and prevention of civilization diseases (49.92\%) and biorhythms (49.08\%) were shown to invoke the partial interest of the surveyed students. On the other hand, many members of our study group did not have any interest in gaining knowledge on topics such as: problems with pregnancy $(76.40 \%)$, drug use and its consequences (48.94\%), and physical activity programs and guidelines (47.93\%) (Table 6).

Table 6: Knowledge on public health gained in voluntary lessons

\begin{tabular}{|c|c|c|c|c|c|c|c|c|}
\hline \multirow{3}{*}{ Subjects } & \multicolumn{8}{|c|}{ I am interested in the following subjects } \\
\hline & \multicolumn{2}{|c|}{ Fully } & \multicolumn{2}{|c|}{ Partly } & \multicolumn{2}{|c|}{ Not at all } & \multicolumn{2}{|c|}{ Total } \\
\hline & $\mathrm{N}$ & $\%$ & $\mathrm{~N}$ & $\%$ & $\mathrm{~N}$ & $\%$ & $\mathrm{~N}$ & $\%$ \\
\hline Tiredness \& fatigue & 150 & 24.92 & 174 & 28.90 & 278 & 46.18 & 602 & 100 \\
\hline First aid & 264 & 41.71 & 289 & 45.66 & 80 & 12.64 & 633 & 100 \\
\hline Sexuality & 300 & 48.78 & 259 & 42.11 & 56 & 9.11 & 615 & 100 \\
\hline Social skills & 287 & 46.67 & 225 & 36.59 & 103 & 16.75 & 615 & 100 \\
\hline Daily rhythm of work and rest & 223 & 37.23 & 294 & 49.08 & 82 & 13.69 & 599 & 100 \\
\hline Civilization diseases & 139 & 22.46 & 309 & 49.92 & 171 & 27.63 & 619 & 100 \\
\hline Psychological and social health hazards & 193 & 31.38 & 270 & 43.90 & 152 & 24.72 & 615 & 100 \\
\hline Ethics and culture of sexual life & 221 & 34.69 & 237 & 37.21 & 179 & 28.10 & 637 & 100 \\
\hline Methods of reducing and coping with stress & 259 & 40.60 & 235 & 36.83 & 144 & 22.57 & 638 & 100 \\
\hline Study skills & 269 & 44.24 & 170 & 27.96 & 169 & 27.80 & 608 & 100 \\
\hline Proper nutrition & 236 & 37.64 & 288 & 45.93 & 103 & 16.43 & 627 & 100 \\
\hline $\begin{array}{l}\text { Venereal diseases and methods of protection against } \\
\text { them }\end{array}$ & 198 & 32.57 & 278 & 45.72 & 132 & 21.71 & 608 & 100 \\
\hline Monitoring and self-assessment of physical fitness & 185 & 29.51 & 267 & 42.58 & 175 & 27.91 & 627 & 100 \\
\hline Personal hygiene and lifestyle & 81 & 12.92 & 247 & 39.39 & 299 & 47.69 & 627 & 100 \\
\hline Marital maturity & 110 & 18.03 & 243 & 39.84 & 257 & 42.13 & 610 & 100 \\
\hline Nicotine use and its consequences & 145 & 23.50 & 183 & 29.66 & 289 & 46.84 & 617 & 100 \\
\hline Physical activity programmes & 72 & 11.94 & 242 & 40.13 & 289 & 47.93 & 603 & 100 \\
\hline Prevention against colds and building resistance & 190 & 31.15 & 242 & 39.67 & 178 & 29.18 & 610 & 100 \\
\hline Motherhood and fatherhood -family planning & 162 & 26.21 & 209 & 33.82 & 247 & 39.97 & 618 & 100 \\
\hline Alcoholism, causes and consequences & 202 & 32.22 & 275 & 43.86 & 150 & 23.92 & 627 & 100 \\
\hline $\begin{array}{l}\text { Purpose and effectiveness of everyday physical } \\
\text { culture }\end{array}$ & 89 & 14.02 & 264 & 41.57 & 282 & 44.41 & 635 & 100 \\
\hline Differences in male and female health behaviours & 98 & 15,71 & 240 & 38,46 & 286 & 45,83 & 624 & 100 \\
\hline Problems with pregnancy and its protection & 59 & 10.02 & 80 & 13.58 & 450 & 76.40 & 589 & 100 \\
\hline Drug use & 140 & 22.84 & 173 & 28.22 & 300 & 48.94 & 613 & 100 \\
\hline
\end{tabular}

\section{Discussion}

The Our studies clearly indicate that physical activity is not a priority among $1^{\text {st }}$ year university students because few of them felt that P.E. lessons should be obligatory throughout their university education and many deemed them as completely unnecessary. Furthermore, those students who did feel it was important to attend P.E. lessons at university wished to do so at a recreational rather than sports level, which reflects their lack of interest in participating in sports. The unwillingness of students to take part in various forms of physical activity $(19,20)$ probably dates back to their earlier years when many behavioral and physiological changes occur (21). During this period adolescents become focused on other matters which take priority over physical activity (e.g., the opposite sex, appearance, pop culture etc.), and tend to 
lose interest in sport if not encouraged by positive role models (22). This is supported by the results of our survey which revealed that the vast majority of students attended only obligatory P.E. lessons and limited themselves to only one or two forms of physical activity. Sports participation in the European Union and its member states still depends on social status, age, gender, income, and education level (2). For example, children from well-off families tend to be more engaged in sports as their parents can afford to pay coaches, cover travel expenses etc (23). One possible reason as to why Polish students do not often participate in sports and recreation is that they often undertake additional work and studies, and therefore do not have sufficient free time or finances.

Despite the above, students questioned in our survey tended to have a rather high opinion of themselves in terms of physical fitness. However, this is not a good indication of the student's actual physical condition, as it is contradicted by their answers regarding the forms of physical activity (or rather the lack of) that they undertook. Moreover, this social group is well known for highlighting attributes which they may not even posses as a result of peer pressure and the need to impress others $(10,11)$.

It is surprising, that nearly all students considered everyday hygiene to be the most important pro-health activity, when choosing from other key factors such as nutrition and physical fitness. It is a well known fact that a proper diet and an adequate level of physical fitness are crucial elements of good health but do not seem to be regarded as such by university youth $(8,24,25)$. Although it is commonly agreed that university students don't pay much attention to proper nutrition and are characterized by rather negative eating habits (26) most of our respondents felt that the current influence of their nutrition was positive and even more of them believed it would continue to be positive in the future.

Information obtained from our research regarding university students' drinking habits is very worrying. Although we cannot expect students to completely abstain from drinking alcohol (only about 3\% of our respondents confirmed doing so) the fact that a significant percentage of them drink habitually and even every day must be brought to attention. People who drink alcohol more than once or twice a week may be alcoholics or run the risk of becoming ones in the future. A similar phenomenon has been observed in countries such as the United States, where binge drinking was found to occur frequently among American university students (27). Europe is not exception to this. In Ireland, the percentage of men who declared drinking alcohol above the weekly recommended units was $52.21 \%$ (28). According to a study conducted by Stock et al. (15) many men from Germany (30\%), Poland (28\%), and Lithuania (26\%), were found to have a problem with drinking. Another indicator that alcohol has taken on an important role in university students' lives is that nearly all questioned men approved of selling alcohol on campus.

As far as smoking is considered, nearly half of $1^{\text {st }}$ year university male students smoke, although not necessarily regularly. Almost $50 \%$ of smokers would like to give up this harmful habit but approximately one third would not, with another $17 \%$ not having any opinion on the subject. On the contrary, studies conducted of seven universities throughout the United Kingdom revealed that $71 \%$ of students had never smoked (29), which is slightly higher than in the U.S., where $65 \%$ of university students reported not having direct contact with cigarettes (30). A similar tendency was observed in other European countries such as Spain, Germany, and Lithuania, where approximately three quarters of university students were non-smokers or only smoked on a few particular occasions (31). It is not surprising that nearly $17 \%$ of students in our studies reported that smoking cigarettes relieves mental tension. A similar finding was observed in a study on Australian students (32).

University life is full of stressful situations. Young adults are forced to make many lifealtering decisions, which often cause them to be overly stressed (33). Such situations are usually more extreme during exam sessions, as well as 
routine tests. This was confirmed by our studies in which over $13 \%$ of surveyed men feared such situations. In order to develop a resistance to stress, appropriate exercises and techniques are found to be very helpful and should be included in the university study curriculum (34). It should however be noted that it is the students themselves who should express the desire to participate in such programs. Our studies showed that $1^{\text {st }}$ year university students were in fact interested in gaining knowledge on this topic. Other even more popular topics included sexuality, improving social skills, study skills and mental health, and first aid.

On the other hand, topics such as: problems with pregnancy, consequences of drug use and physical activity programs were not found to grab the attention of members of our study group. Since students were not interested in gaining knowledge on numerous topics, many of which are essential to good health, it would appear that UWM students do not take their health seriously. A similar and worrisome trend was also observed among Malaysian and Australian students of medicine, who were not found to possess adequate knowledge regarding human sexual and reproductive health (35).

\section{Conclusion}

The habits of $1^{\text {st }}$ year university male students do not promote a healthy life. The overwhelming majority of them cannot be considered to have led a physical activity lifestyle during secondary school and at the beginning of their university studies, and many of them did not even express an interest in doing so in the foreseeable future. Nearly all students consume alcohol and a significant percentage of them drink habitually, as often as every day. Nearly half of the surveyed students smoke cigarettes, although not necessarily regularly. The majority of students considered stressful situations to be unavoidable and were not able to indicate more than one method of coping with stress. They did, however, express an interest in gaining knowledge on this subject. On the whole, most pro-health topics did not trigger the interest of $1^{\text {st }}$ year male university students. The studies should be continued in further years to see if any changes in the habits and attitudes of students have taken place, determine the direction of these changes, and develop a strategy that would facilitate improvement in the years to come.

\section{Reference}

1. Stacy Turconi G, Guarcello M, Maccarini L, Cignoli F, Setti S, Bazzano R Roggi C. Eating Habits and Behaviors, Physical Activity, Nutritional and Food Safety Knowledge and Beliefs in an Adolescent Italian Population. JACN. 2008; 27(1): 3143.

2. Van Tuyckom C., Scheerder J. Sport for All? Insight into stratification and compensation mechanisms of sporting activity in the 27 European Union member states. Sport Educ Soc. 2010; 15(4): 495512.

3. Galobardes B, Costanza MC, Bernstein MS, Delhumeau C, Morabia A. Trends in Risk Factors for Lifestyle-Related Diseases by Socioeconomic Position in Geneva, Switzerland,1993-2000: Health Inequalities Persist. Am J Public Health. 2003; 93(8): 1302-1309.

4. Entala-Bueno A, Iglesias C, de Jesus F. Diet and physical activity: a healthful binominal. Eur J Clin Nutr. 2003; 57(suppl. 1): 63-65.

5. Schuit AJ. Physical activity, body composition and healthy ageing. Science \& Sports. 2006; 21(4): 209-213.

6. Warburton DER, Nicol CW, Bredin SSD. Health benefits of physical activity: the evidence. CMAJ. 2006; 174 (6): 801-809.

7. Miazek U, Chrzanowska M, Miazek Z. Psychical activity in student lifestyle in the light recommendation of health promotions experts. Ann Univ Mariae Curie Skłodowska Lublin - Polonia. 2005; LX(316): 414-418.

8. Gacek M, Frączek B. Physical activity as a remedial element in psychological stress reduction among the youth. Ann Univ Marie Curie-Skłodowska Lublin-Polonia, Sectio D, 2005; 16(107): 496-499.

9. Podstawski R. Physical ability and opinions on health prevention among the $1^{\text {st }}$ year students at the University of Warmia \& Mazury in Olsztyn in academic year 1999/2000. Olsztyn: UWM Press; 2006.

10. Podstawski R. Pro health attitudes of first year students attending the University of Warmia \& Mazury in Olsztyn on health 
(2001/2002). In Urniaż M, editors. Sport i Wychowanie Zdrowotne. Olsztyn: OSW Press; 2011. p. 59-75.

11. Podstawski R, Górnik K, Gizińska R, Skibniewska KA. Pro-health attitudes towards health prevention of $1^{\text {st }}$ grade students attending the University of Warmia \& Mazury in Olsztyn (2003/2004). In Sokołowska B, editors. Public Health in the Aspect of Modern Civilization. Biała Podlaska: PSWJPII Press; 2012. p. 62-78.

12. Webb E, Ashton CH, Kelly P, Kamali F. Alcohol and drug use in UK university students. The Lancet. 1996; 348(9032): 922925.

13. Steptoe A, Wardle J, Cui W, Bellisle F, Zotti AM, Baranyai R, Sanderman R. Trends in smoking, diet, physical exercise, and attitudes toward health in European university students from 13 countries, 19902000. Prev Med. 2002; 35(2): 97-104.

14. Haase A, Steptoe A, Phil D, Sallis JF, Wardle J. Leisure-time activity in university students from 23 countries: association with health beliefs, risk awareness, and national economic development. Pre. Med. 2006; 39: 182-190.

15. Stock C, Mikolajczyk R, Bloomfield K, Maxwell AE, Ozcebe H, Petkeviciene J, et al. Alcohol consumption and attitudes toward banning alcohol sales on campus among European university students. Public Health. 2009, 123: 122-129.

16. Zieliński R., Zieliński W. Tablice statystyczne. Warszawa: Fundacja Rozwój SGGW Press; 2001.

17. Nowak E. Outline of econometric methods. Warsaw: PWN; 2002.

18. Stanisz A. Practical course in statistics with STATISTICA PL using examples from medicine. Cracow: StatSoft Polska; 2001.

19. Negasheva MA, Mishkova TA. Morphofunctional Parameters and Adaptation Capabilities of Students at the Beginning of the third Millennium. J Physiol Anthropol Appl Hum Sci. 2005; 24(4): 397402.

20. Stelzer J, Ernest JM, Fenster MJ, Langford G. Attitudes toward Physical Education: A Study of High School Students from Four Countries - Austria, Czech Republic, England, and USA. College Student Journal. 2004; 38(2): 171-179.

21. Gordon-Larsen P, Adair LS, Nelson MC, Popkin BM. Five-year obesity incidence in the transition period between adolescence and adulthood: the National longitudinal
Study of Adolescent Health. Am J Clin Nutr. 2004; 80: 569-575.

22. LaCaille LJ, Dauner KN, Krambeer RJ, Pedersen J. Psychosocial and Environmental Determinants of Eating Behaviors, Physical Activity, and Wieght Changes Among College Students: A Qualitative Analysis. J Am Coll Health. 2011; 59(6): 531-538.

23. Vandendriessche JB, Vandorpe BF, Vaeyens $\mathrm{R}$, Malina RM, Lefevre J, Lenoir $M$, Philippaerts RM. Variation in sport participation, fitness and motor coordination with socioeconomic status among Flemish children. Pediatr Exerc Sci. 2012; 24(1): 113-128.

24. Levitsky DA, Halbmaiier CA, Mrdjenovic G. The freshman weight gain: a model for the study of the epidemic of obesity. Int $\mathbf{J}$ Obes. 2004; 28: 1435-1442.

25. American College Health Association. American college Health Association National college Health assessment (ACHANCHA) Spring 2005 Reference Group Data Report (Abridged). J Am Coll Health. 2006; 55(1): 5-16.

26. Lowry R, Galuska DA, Fulton JE, Wechsler H, Kann L, Collins JL. Physical activity, food choice and weight management goals and practices among U.S. college students. Am J Prev Med. 2000; 18: 18-19.

27. Wechsler H, Nelson T. What We Have Learned From the Harvard School of Public Health College Alcohol Study: Focusing Attention on College Student alcohol Consumption and Environmental Conditions that Promote It. J Stud Alcohol Drugs. 2008; 69(4): 481-490.

28. Harrington J, Perry IJ, Lutomski J, Fitzgerald AP, Shiely F, McGee H, et al. Living longer and feeling better: healthy lifestyle, self-rated health, obesity and depression in Ireland. Eur J Public Health. 2010; 20(1): 91-95.

29. Ansari WE, Stock C, John J, Deeny P, Phillips C, Snelgrove S, et al. Health promoting behaviours and lifestyle characteristics of students at seven universities in the UK. Cent Eur J Public Health, 2011; 19(4): 197-204.

30. American College Health Association. American college Health Association National College Health Assessment Spring 2006 Reference Group Data Report (Abridged). J Am Coll Health. 2007; 55(4): 195-206.

31. Stock C, Kücük N, Miseviciene I, GuillénGrima F, Petkieviciene J, Aguinaga-Ontoso 
I, et al. Differences in health complaints among university students from three European countries. Prev Med. 2003; 37(6): 535-543.

32. Sun J, Buys N, Stewart D, Shum D, Farquhar L. Smoking in Australian university students and its association with socio-demographic factors, stress, health status, coping strategies, and attitude. Health Education, 2010; 111(2): 117 - 132.

33. Bayram N, Bilgel N. The prevalence and socio-demographic correlations of depression, anxiety and stress among a group of university students. Soc. Psychiatry Psychiatr. Epidemiol. 2008; 43: 667-672.

34. Ma Z. Cognition and Practice of strengthening Psychological Health Education among University Students in a New Period. Asian Social Science. 2010; 6(10): 83-87.

35. Shaiful Bahari I, Rosediani M, Nik Hazlina NH, Shamsunarnie MZ, Leon P. Knowledge on male sexual and reproductive health: a comparison between final year medical students in University Sains Malaysia (USM) and Monash University (MU), Melbourne, Australia. Education in Medicine Journal. 2012; 4(2): 45-58. 